\title{
Condition assessment of reinforced concrete beams - Comparing digital image analysis with optic fibre Bragg gratings
}

\author{
Elsabe Kearsley, ${ }^{1, *}$ and $S W$ Jacobsz $^{1}$ \\ ${ }^{1}$ Department of Civil Engineering, University of Pretoria, South Africa
}

\begin{abstract}
Reinforced concrete is the most widely used construction material and thus effective condition assessment of reinforced concrete elements forms a significant part of structural health monitoring. An effective structural health monitoring system should be able to give the owner prior warning that structural elements are reaching conditions approaching either serviceability or ultimate limit states. The aim of this investigation is to compare strain data recorded during load testing of a reinforced concrete beam using Fibre optic Bragg Gratings (FBG) and a photographic technique to determine circumstances most suitable for the use of each of the techniques. The test results indicate that FBG sensors can be used to detect small strains as well as large strains in uncracked concrete elements, while optical images can be used to accurately map crack development over the surface area of the structure.
\end{abstract}

\section{Background}

The high cost associated with construction of large infrastructure motivates owners to extend the useable life of infrastructure, by means of condition assessment, maintenance and rehabilitation, as and when required. Effective structural health monitoring is becoming more important as timeous repair can extend the lifespan of infrastructure. Reinforced concrete is the most widely used construction material, thus effective condition assessment of reinforced concrete elements forms a significant part of structural health monitoring.

Reinforced concrete elements are designed assuming that bending moments are resisted by concrete in areas of compression and steel in areas experiencing tensile stresses. Structures are designed assuming that concrete cannot resist tensile forces and crack widths of up to $0.3 \mathrm{~mm}$ are acceptable under serviceability load conditions [1]. In terms of condition assessment, this means that concrete structures can be either un-cracked or cracked while still fully serviceable. During condition assessment, the observation of large deformations or crack widths exceeding specified limits would be seen as failure in terms of serviceability. Ultimate failure will only take place when the steel stress exceeds the yield strength (elastic limit), or when the cross-sectional area of the un-cracked concrete, in areas of compression, is so small that the stress in the concrete exceeds the compressive strength of the concrete. An effective structural health monitoring system would be able to give the owner prior warning that structural elements are reaching a condition approaching serviceability or ultimate limit states.
When Dunnicliff wrote his book on instrumentation for monitoring field performance in 1988, strain gauges were deemed to be the most appropriate method for determining the strain in reinforced concrete [2].

Mechanical or electrical strain gauges can be surface mounted or embedded. Embedment strain gauges have an "inclusion effect", whereby the presence of the gauge distorts the strain field so that the measured strain differs significantly from the strain that would occur if the gauge was not present. The measurement error is limited if the volume of concrete surrounding the gauge is large relative the size of the gauge and the concrete is in compression. Bond between the gauge and the concrete is not an issue, as long as the gauge stiffness is significantly lower than that of the surrounding concrete and the gauge length exceeds five times its diameter [2].

Although strain measurement of reinforced concrete has been performed for many decades, limited information is available to quantify and compare the effect of surface mounted and embedded mechanical and electrical strain gauges in both the compression and tension zones of reinforced concrete elements. The use of strain gauges to monitor the behaviour of reinforced concrete elements has been limited by the fact that every gauge needs to be connected to a data acquisition system with a durable and shielded electric cable and these cables are prone to electromagnetic interference, corrosion and attack by rodents.

In the recent past, the use of fibre optic sensors in the form of Fibre Bragg Gratings (FBG) have been found to be useful in detecting both strain and crack formation [3, 4]. The main advantage of Bragg gratings is that up to 20

* Corresponding author: Elsabe.kearsley@up.ac.za 
strain sensors can be monitored using only one optic fibre, thus significantly reducing the cost and risks associated with cabling. The protective coating around the glass fibre makes it a durable system, perfectly suited for long-term data acquisition, but there are still questions about the transfer of strains between the concrete, the coating and the glass core of these fibres. Although FBGs have been used in various reinforced concrete structures, these gratings were mostly encapsulated in or placed on relatively rigid metal or glass fibre coatings, tubes and plates [5, 6], which can still affect the readings due to the size and stiffness effect of the sensor.

In this project the FBG sensors were cast into the concrete as a continuous $2 \mathrm{~mm}$ diameter coated glass fibre strand. The small size and stiffness of the strand would not affect local strains. However, slip may potentially occur between the glass fibre and the coating, or the coating and the concrete, beyond a certain strain limit, resulting in incorrect strain readings.

As concrete is known to be a non-homogeneous, nonisotropic material, it is impossible to know exactly where cracks in a structure would form. Any discrete measurement system, comprising of gauges at discrete positions, would be unable to detect cracks that form adjacent to the area that affects the strain recorded by the gauge. Digital Image Correlation (DIC) has been used to record strain measurements by taking the relative movement of patches of pixels in a series of photos into account, thus making it possible to monitor the whole surface of a concrete element [7]. To date limited information has been published on the use of digital image correlation as a structural health monitoring tool, which can be used to warn owners of crack growth and excessive deformations.

The aim of this investigation is to compare the data recorded using different measurement techniques, thus determining circumstances most suitable for the use of each of the techniques. Techniques under consideration include cast-in and surface mounted optical fibre Bragg gratings, digital image analysis, concrete and vibrating wire strain gauges, Linear Variable Differential Transformers (LVDT's) as well as surface mounted and cast in Wheatstone bridge strain gauges. In this paper the results obtained from digital image correlation are compared to strain measurements from optical Bragg grating readings.

\section{Experimental setup}

The aim of the experimental work was to compare the results obtained when using different measurement techniques against theoretically predicted values in an effort to rank techniques for structural health monitoring in terms of the most appropriate techniques for:

- measuring small strains in uncracked concrete,

- detecting the formation of hairline cracks (typical range of $0.1 \mathrm{~mm}$ to $0.3 \mathrm{~mm}$ ) in reinforced concrete under normal serviceability conditions,

- recording ultimate limit state and failure conditions when large tensile cracks in the concrete have formed, the steel in reinforced concrete starts yielding and the concrete starts failing in compression.

A $150 \mathrm{~mm}$ wide, $230 \mathrm{~mm}$ deep and $2 \mathrm{~m}$ long reinforced concrete beam was cast containing two $12 \mathrm{~mm}$ high yield steel bars placed on $20 \mathrm{~mm}$ cover blocks in the bottom of the beam and two $5.6 \mathrm{~mm}$ steel bars with $20 \mathrm{~mm}$ concrete cover from the top of the beam. Shear stirrups $(5.6 \mathrm{~mm}$ diameter bars) were placed at $100 \mathrm{~mm}$ centres. The concrete mix composition is presented in Table 1 . The compressive strength of the concrete was measured using $150 \mathrm{~mm}$ cubes while the modulus of elasticity was recorded using a standard collar over the central $167 \mathrm{~mm}$ of a $300 \mathrm{~mm}$ long $150 \mathrm{~mm}$ diameter cylinder. Cracking strength was estimated from split cylinder strength values, obtained from $150 \mathrm{~mm}$ diameter cylinders. All reported values are average values, from sets of two specimens tested respectively 1,4 and 7 days after casting. To ensure that the measured concrete properties matched that of the concrete in the beam, all the concrete cast was left in the same room and demoulded at the same age. Concrete was thus tested in an unsaturated condition. To limit the risk of readings being affected by drying shrinkage cracks forming in the beam, the beam was tested 7 days after casting.

Table 1. Concrete mix composition.

\begin{tabular}{|l|c|c|}
\hline Material & $\begin{array}{c}\text { Relative } \\
\text { Density }\end{array}$ & $\mathbf{k g} / \mathbf{m}^{\mathbf{3}}$ \\
\hline Cement (Cem II A-V 42.5R) & 3.02 & 413 \\
\hline Water & 1.00 & 215 \\
\hline Dolomite stone (10mm) & 2.84 & 877 \\
\hline Dolomite crusher sand & 2.84 & 965 \\
\hline
\end{tabular}

The early age concrete strength and stiffness can be seen in Table 2. These results show the increase in concrete strength and stiffness up to the day of testing ( 7 days after casting). After 7 days the concrete should remain un-cracked up to tensile stresses of $3.03 \mathrm{MPa}$. Given a modulus of elasticity of $34.9 \mathrm{GPa}$, this stress will be reached at a strain of $87 \mu \varepsilon$, assuming uniaxial conditions.

The stress-strain behaviour during tensile testing of the reinforcement bars can be seen in Fig. 1. Both the $12 \mathrm{~mm}$ and $5.6 \mathrm{~mm}$ high yield steel bars have theoretical yield strengths of $450 \mathrm{MPa}$ and these results indicate that it would be fair to assume that the steel behaviour would be linear elastic at strains up to 2000 microstrain.

The modulus of elasticity for the steel was measured as $215.9 \mathrm{GPa}$ and $221.4 \mathrm{GPa}$ for the $12 \mathrm{~mm}$ and $5.6 \mathrm{~mm}$ reinforcement bars respectively. 
Table 2. Concrete properties.

\begin{tabular}{|l|c|c|c|}
\hline Property & $\begin{array}{c}\mathbf{1} \\
\text { day }\end{array}$ & $\begin{array}{c}\mathbf{4} \\
\text { day }\end{array}$ & $\begin{array}{c}7 \\
\text { day }\end{array}$ \\
\hline Compressive strength (MPa) & 13.0 & 31.8 & 37.2 \\
\hline Split cylinder strength $(\mathrm{MPa})$ & 1.33 & 2.74 & 3.03 \\
\hline Modulus of Elasticity $(\mathrm{GPa})$ & 23.4 & 33.0 & 34.9 \\
\hline
\end{tabular}

The beam was demoulded 4 days after casting and on the 5th day the beam was moved to the outdoor test facility and placed on roller supports to span $1.8 \mathrm{~m}$. The beam was tested 7 days after casting by loading it incrementally at third points. Strains obtained from surface mounted FBG sensors were compared to that from cast-in sensors and theoretical strain values.

A number of load cycles were applied including:

- Two cycles (Cycle 1 and Cycle 2) where the beam was loaded and unloaded in steps of $2 \mathrm{kN}$ up to $10 \mathrm{kN}$ to compare measuring techniques for evaluation of un-cracked reinforced concrete (or strains below $100 \mu \mathrm{m})$.

- A cycle where the load was increased to induce the first cracks, thus allowing comparison of measuring techniques for crack detection in reinforced concrete (Cycle 3).

- A cycle where the beam was loaded and unloaded in steps of $4 \mathrm{kN}$ to compare measuring techniques for monitoring the behaviour of cracked reinforced concrete (Cycle 4).

- A cycle where the beam was loaded to ultimate limit state (Cycle 5).

Using the beam dimensions, statically determinate support and load conditions (see Fig. 2), as well as the measured material properties, it is possible to predict the strain distribution in the beam, as well as the load that will cause the beam to firstly crack and later fail in bending as indicated in Fig. 3. From Fig. 1 it can be seen that significant strain-hardening took place after yielding of the steel bars and, as a result, the ultimate load that the beam can carry when the concrete starts failing in compression should be approximately $77.7 \mathrm{kN}$.

Load was applied in $2 \mathrm{kN}$ or $4 \mathrm{kN}$ steps at 5 minute intervals and load, as well as midpoint deflection, internal strains and digital images were recorded during each load increment.

A string of fibre optic Brag gratings with wavelengths between $1510 \mathrm{~nm}$ and $1586 \mathrm{~nm}$ was cast into the beam. The $8 \mathrm{~mm}$ long gratings were spaced at $1 \mathrm{~m}$ intervals along a $125 \mu \mathrm{m}$ optical fibre. The fibre was coated with Glass Fibre Reinforced Polymer (GFRP) and high density polyethylene (HDPE), resulting in a final diameter of $2 \mathrm{~mm}$. The fibre sensors were installed in the beam, so that all twenty Bragg gratings were located along the mid-span cross-section of the beam, as indicated in Fig. 4.
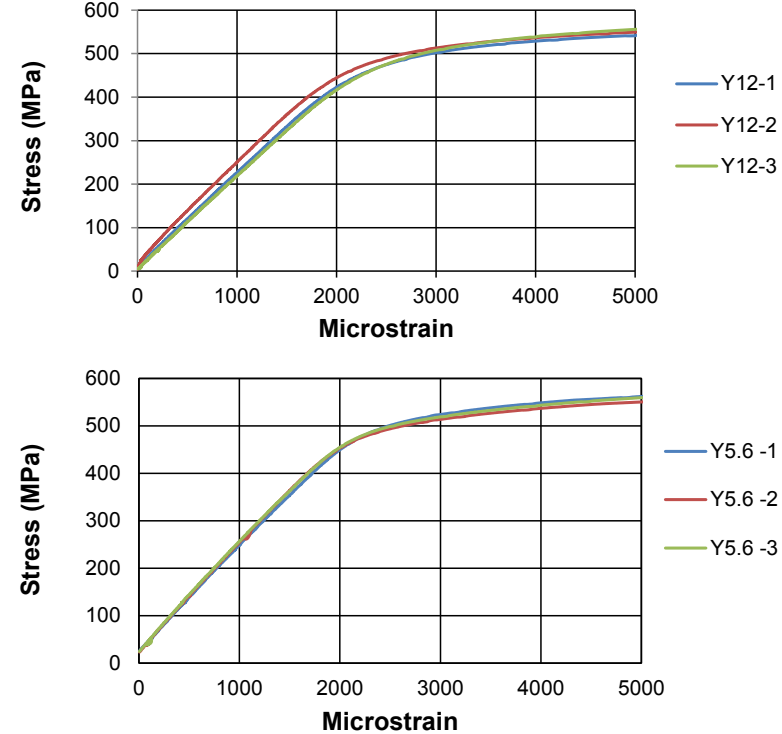

Fig. 1: Stress-strain behaviour of steel reinforcement

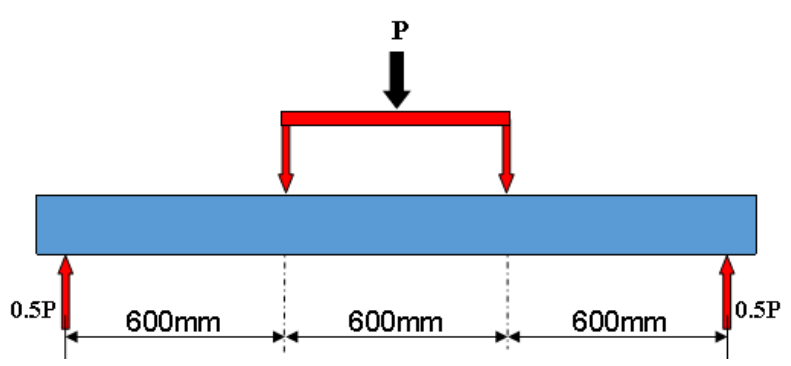

Fig. 2: Loading of beam.

Image analysis was conducted using a Digital Single Lens Reflex (DSLR) camera recording images of $2560 \mathrm{x}$ 1920 pixel resolution at one minute intervals. Black spray paint was used to generate texture on the concrete surface, necessary for the image processing software. Particle Image Velocimetry software (GeoPIV), developed by White et al. [8], was used to track a grid of square pixel patches, with the aim of calculating the displacement field across the surface of the beam. From the displacement field it is possible to calculate any desired strain field.

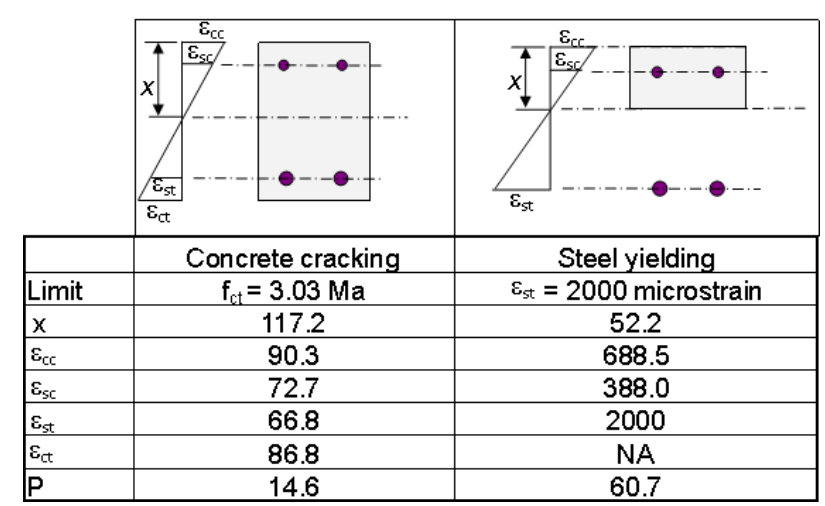

Fig. 3: Calculated crack and yield limits. 


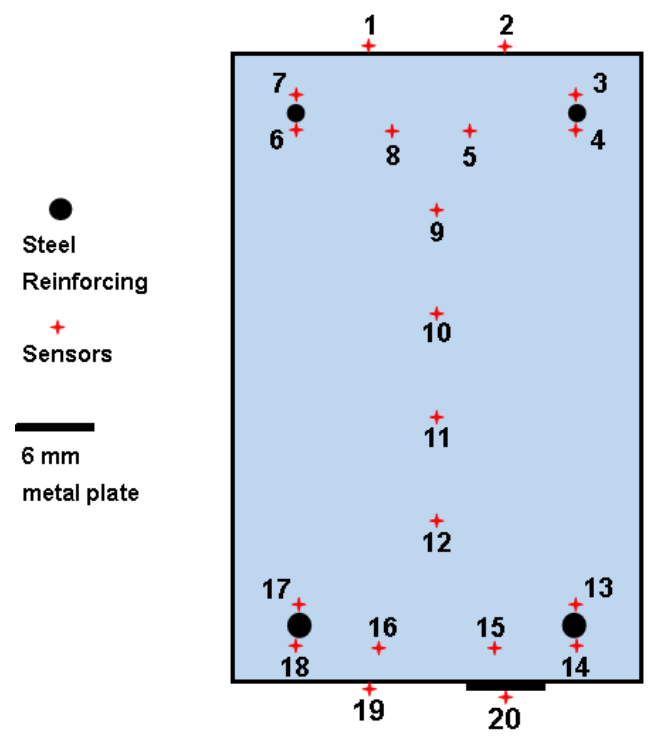

Fig. 4: Beam cross section indicating optical gauges

\section{Experimental results}

\subsection{Load deflection behaviour of beam}

The load sequence applied to the beam during the testing program is presented in Fig. 5, showing the applied load versus midpoint deflection. The first two load cycles caused limited deflection and insignificant permanent deformation. It is clear that the first cracks formed during the $3^{\text {rd }}$ load cycle.

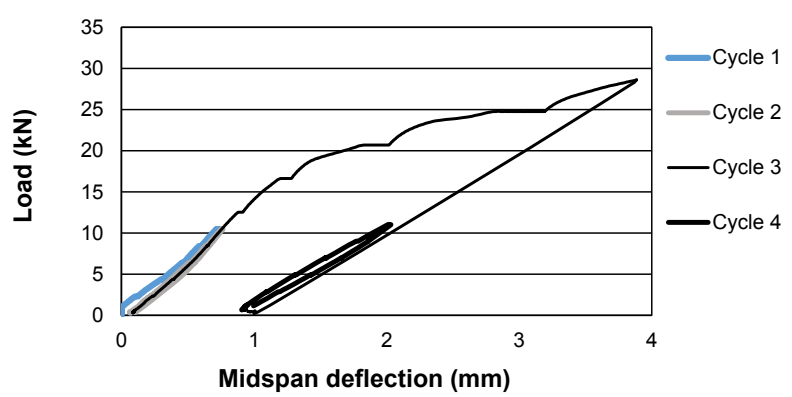

Fig. 5: Load deflection behaviour of beam

The vertical movement of the beam, recorded using patches near the beam midspan, was compared to the midspan LVDT readings for the $3^{\text {rd }}$ load cycle as can be seen in Fig. 6. These results indicate that small deflection of structural elements can be accurately detected from a distance through image analysis.

In addition, the load-deflection behaviour of the beam during the $3^{\text {rd }}$ and $5^{\text {th }}$ load cycles can be seen in Fig. 7. When the load for the first time exceeded approximately $15 \mathrm{kN}$, in the $3^{\text {rd }}$ load cycle, a significant reduction in stiffness is evident, as the rate of increase in deflection suddenly increased for constant load increments. The load deflection behaviour graphs indicated that, as expected, the first cracks in the beam developed at a load of approximately $15 \mathrm{kN}$.

During the $5^{\text {th }}$ load cycle the load was increased to $82 \mathrm{kN}$ (Fig. 7). It can be seen that the rate of increase in deflection accelerated when the load exceeded about $60 \mathrm{kN}$ and the steel reinforcement started yielding, thus reaching ultimate limit state.

These results show that it is possible to use digital images to, not only detect small deflections in structural elements, but also to detect changes in load-deflection behaviour, similar to what can be achieved using displacement transducers.

\subsection{Pre-cracked strain conditions}

The first load cycle was used to establish the performance of the Bragg gratings at small strains. Strains recorded at mid-span, at different depths through the beam, can be seen in Fig. 8. These results indicate that strain differences as small as a couple of microstrain can be clearly distinguished, in both tension and compression, using embedded optic fibres. This represents a significantly higher level of precision than what has historically been possible.

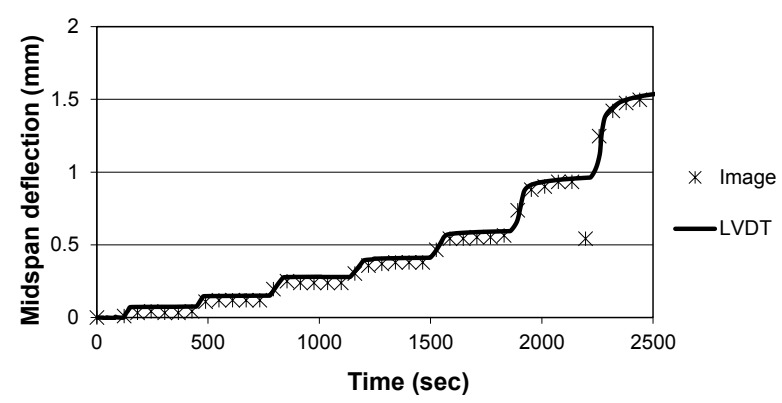

Fig. 6: Midspan deflection for $3^{\text {rd }}$ load cycle.
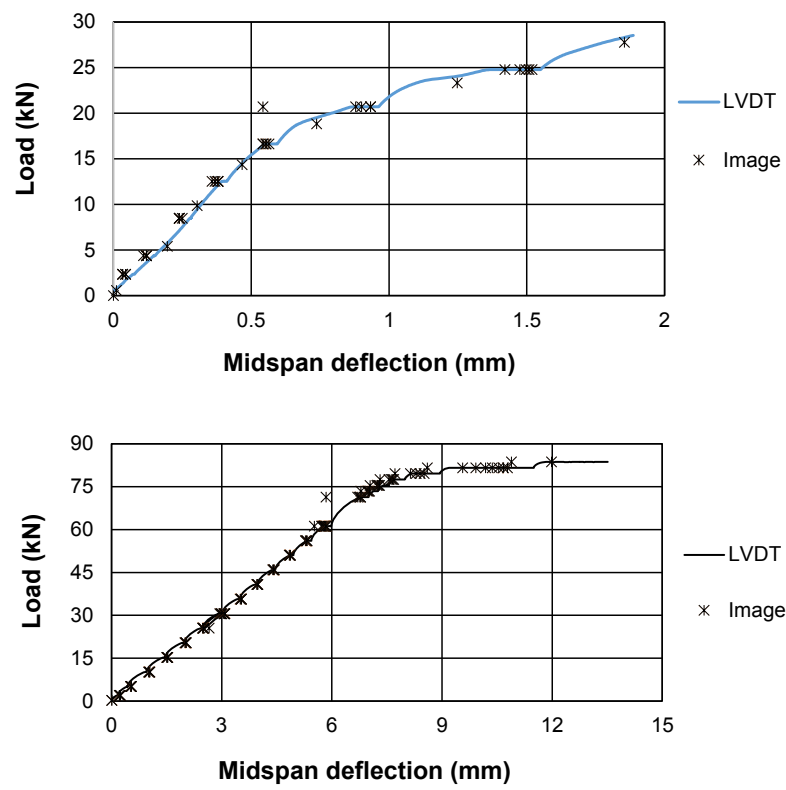

Fig. 7: Behaviour for $3^{\text {rd }}$ and $5^{\text {th }}$ load cycle.

Image analysis was conducted on the photos taken during the first and the second load cycle. By comparing the displacement of patches to their original separation before any load was applied to the beam, it is possible to calculate strains in the concrete beam. An example of a 
patch layout suitable for the calculation of horizontal strain across the depth of the beam can be seen in Fig. 9. No noticeable strains were detected at low loads (less than about $10 \mathrm{kN}$ ) and image analysis is not deemed to be a suitable technique for measuring very small strains.

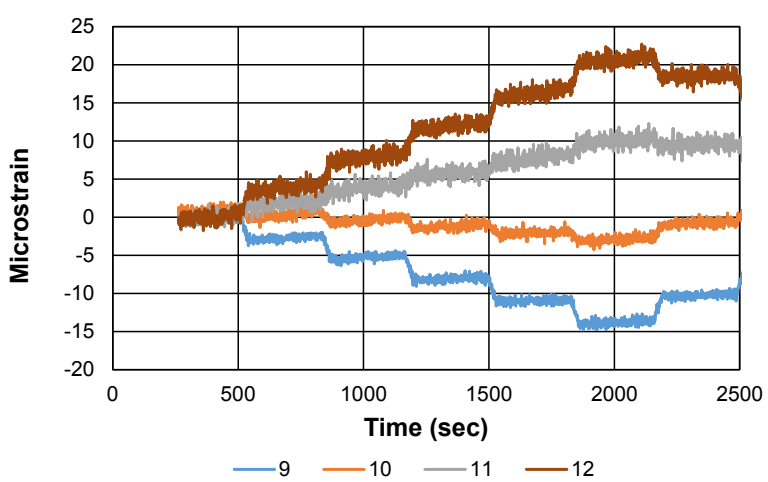

Fig. 8: Bragg grating readings for first load cycle.

\subsection{Crack formation}

Although patches on digital images as indicated in Fig. 9 cannot be used to measure small strains in uncracked concrete, it can be used to detect crack formation. The change in horizontal distance between the two columns of patches (600 pixels or $62.58 \mathrm{~mm}$ apart), as indicated in Fig. 9 are presented in Fig. 10 for the $3^{\text {rd }}$ load cycle. The legend in this figure indicates the distance from the top surface of the beam for every pair of patches used. These results clearly indicate that insignificant displacements were observed for loads up to $12 \mathrm{kN}$, whereafter a sudden increase in displacement could be observed for all patches in the bottom half (more than $115 \mathrm{~mm}$ from the top surface), or tension zone, of the beam. This sudden increase in horizontal movement took place when the first structural cracks formed as confirmed by the PIV strain plots in Fig. 11.

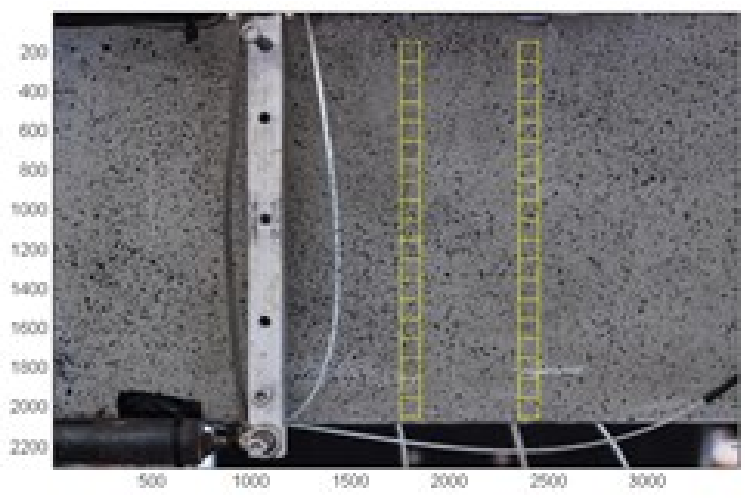

Fig. 9: Patch layout for measuring horizontal strain

Analysis of the digital images indicate that it is possible to use a normal digital camera to observe the formation of cracks, before the crack width reaches $0.1 \mathrm{~mm}$. It is interesting to note from Fig. 10 that the relative horizontal movement of the patches in the bottom section of the cracked beam reduces as the load increases and this is probably caused by the formation of additional cracks along the length of the beam. Strain images, as indicated in Fig. 11, can be used during structural health monitoring to not only accurately map the position and size of small structural cracks, but also provide an indication of the rate of deterioration in terms of changes in recorded crack lengths and widths over a period of time.

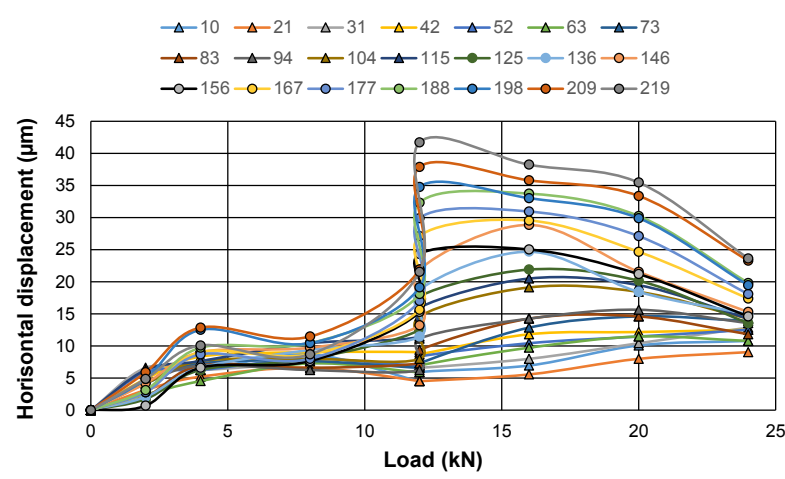

Fig. 10: Crack formation from digital images.

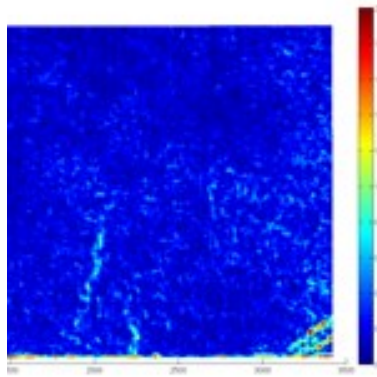

$20 \mathrm{kN}$

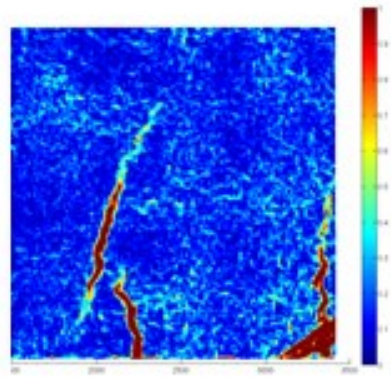

$24 \mathrm{kN}$
Fig. 11: Digital images of crack development.

The strain profile through the depth of the concrete beam, as measured with the FBGs, can be seen in Fig. 12. Although it is not possible to detect the exact location or width of the cracks, the FBGs can be used to detect that cracking in the concrete has occurred in the region of the sensors. It is worth noting that the optic fibre sensors that were glued to the top a surface of the beam (Sensor 1) did not give useable information, indicating that the epoxy-based glue used slipped, or crept, without transferring the compressive strains from the concrete surface to the sensor. Sensor 20 was attached to the bottom of the beam, using epoxy to glue two metal plates to the concrete and clamping the optic fibre to the plates. The clamping plates were positioned $100 \mathrm{~mm}$ apart. The readings obtained from this surface mounted gauge marginally exceeded strain trends obtained from gauges cast into the un-cracked concrete. Once the concrete cracked, the surface mounted gauge recorded values comparable to that of the embedded sensors. Care must be taken when attaching sensors to the surface of reinforced concrete elements to ensure that the strain in the concrete is transferred and accurately measured. The results, as shown in Fig. 12, confirms that planes in reinforced concrete beams remain plane during 
bending. When the tensile strain exceeds the tensile strain capacity of the concrete, cracks form, resulting in significant increases in strain. After the concrete at the bottom of the beam cracked in tension, the reinforcing bars in the bottom of the beam carried additional load, resulting in the localized increase in strain that can be seen at a load of $20 \mathrm{kN}$ in the cracked concrete below these reinforcement bars.

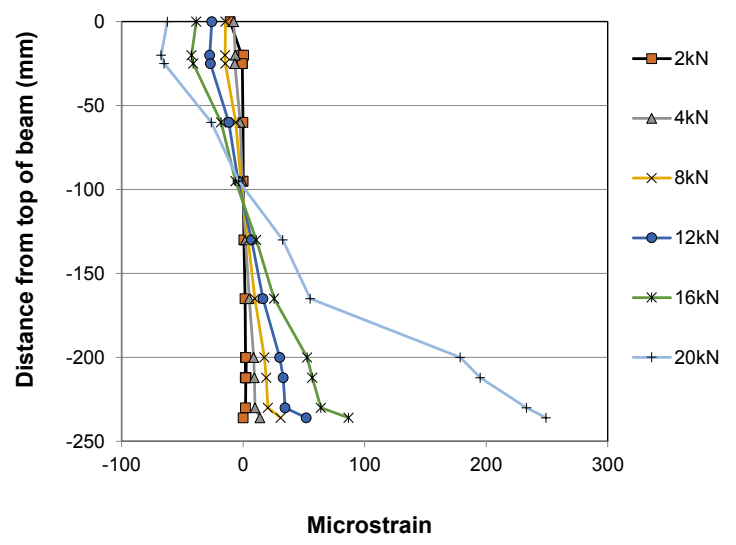

Fig. 12: Strain recorded by optic fibres.

As the crack depth increases, the section stiffness decreases, resulting in constant load increments $(4 \mathrm{kN})$ causing ever increasing strain increments. When a load of $20 \mathrm{kN}$ was applied to the beam, the concrete in the bottom of the beam was cracked and the strains recorded indicates that the cracks in the concrete extended to up to about $100 \mathrm{~mm}$ from the soffit of the beam (where the tensile strain exceeded 87 microstrain).

\subsection{Large strains}

To determine whether there is strain loss between the optic fibre and the concrete in compression, the measured strains were compared to the strain predicted for the cracked beam at every load increment of the $5^{\text {th }}$ load cycle (See Fig 13). The maximum compressive strain in the concrete was calculated using the results from both the FBG glued to the top surface of the beam (Sensor 1) and the FBG cast in $20 \mathrm{~mm}$ from the top surface of the beam (Sensor 3). The results obtained from Sensor 3 was adjusted by assuming planes remain plane during bending and strain increases linearly with the distance from the neutral axis of the section. These results indicate that optic fibre gratings protected with GFRP and HDPE can be used to record concrete compressive strains that match values as assumed during design of reinforced concrete elements. Insignificant slip occurred between the glass fibre and the protective coating as well as between the fibre strand and the concrete. When the load exceeded $30 \mathrm{kN}$ the surface mounted grating debonded, making it impossible to obtain any further sensible readings from this sensor. In terms of long term monitoring of the performance of structures, these results indicate that there would be benefits in casting FBG sensors into structures for structural health monitoring.
It is normally assumed that reinforced concrete structural elements work as composites, with the steel resisting all the tensile stresses and the concrete resisting only compression. The strain in the steel is deemed to be the same than that of the concrete surrounding the bonded steel bars. It is thus necessary to determine whether the strain in the steel can be accurately measured by casting sensors into the concrete adjacent to the steel reinforcing. In this experiment, eight of the FBG sensors were placed adjacent to the reinforcing bars, but not glued to the bars. As indicated in Fig. 4 sensors 13,14, 17 and 18 were positioned above and below the $12 \mathrm{~mm}$ bars in tension and these readings were averaged to compare against the average strain expected in the steel bars in tension for each load interval. Sensors $3,4,6$ and 7 were placed above and below the $5.6 \mathrm{~mm}$ bars and their strain readings were averaged and compared to the calculated strain in the compression zone, at a level $22.8 \mathrm{~mm}$ from the top surface of the beam. From Fig. 14 it can be seen that the strain measured at the level of the compression steel matches the theoretical values for the full range of elastic concrete behaviour. The tensile strains measured compare well with calculated strain values at low loads. Once visible flexural cracks formed in the bottom of the beam, strain readings became dependent on the exact location of the cracks, while the readings became large and unpredictable. The measured strains of FGB sensors that are not glued to reinforcing bars does not give a fair indication of the actual strains in the reinforcing bars after crack formation.

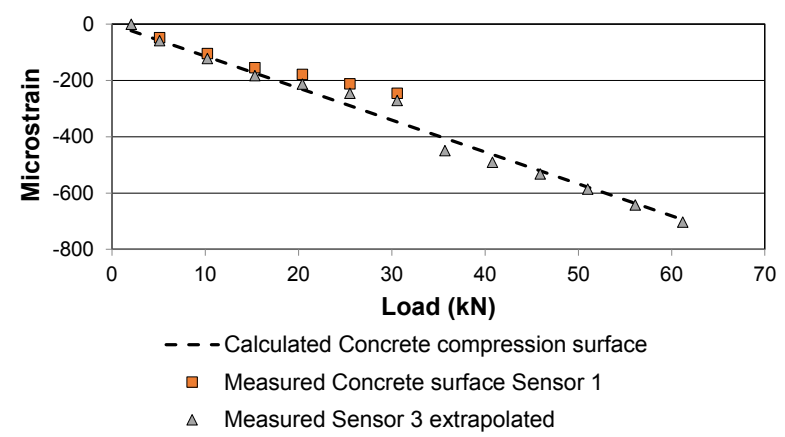

Fig. 13: Concrete strains at large loads.

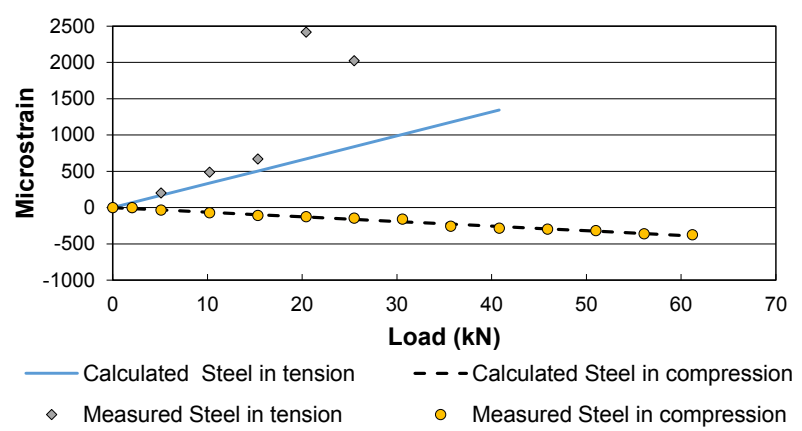

Fig. 14: Steel strains at large loads. 


\section{Conclusions}

Structural health monitoring can be significantly improved by using modern measurement equipment. Digital image analysis and optical fibres Bragg gratings can be used to monitor changes in stress distribution at serviceability and ultimate limit state conditions in concrete beams. Protected optic fibre strands can be cast into concrete elements to accurately measure concrete strain. At low strain levels the high sensitivity of Bragg grating sensors can be utilized to investigate very small strain changes, which cannot be reliable detected using digital images. When sensors are glued to concrete surfaces, compressive strain values may be incorrectly measured due to strain losses caused by the bonding agent. Both glued and clamped gauges gave acceptable tensile strain readings at low loads. When flexural cracks open up at higher loads, the strain readings obtained from FBG sensors can only be used as indicators that cracking has occurred. Embedded FBG sensors give reliable compressive strain readings up to failure.

Although crack detection is possible using either technique, digital images can cover large areas, which means that cracks can be detected in larger areas than what would be possible with discrete sensors. A combination of these techniques would give the best structural health monitoring results.

\section{References}

1. International Federation for Structural Concrete (fib), 2013 fib Model Code for Concrete Structures 2010, Ernst \& Sohn (2013).

2. J. Dunnicliff, Geotechnical Instrumentation for Monitoring Field Performance. John Wiley \& Sons, USA (1988).
3. L. Butler, N. Gibbons, C. Middleton \& M. Elshafie, Integrated fibre-optic sensor networks as tool for monitoring strain development in bridges during construction. 19th IABSE Congress, Stockholm, (2016).

4. C.K.Y. Leung, K.T. Wan, D. Inaudi, X. Bao, W. Habel, Z. Zhou, J. Ou, M. Ghndehari, H.C. Wu \& M. Imai, Review: optical fiber sensors for civil engineering applications, Materials and Structures 48, 871 - 906 (2015).

5. Y.Yao, S.E. Tung \& B. Glisic, Crack detection and characterization techniques - An overview, Struct. Control Health Monit. 21, 1387 - 1413 (2014).

6. N. Tondini, O. S. Bursi, A. Bonelli \& M Fassin, Capabilities of a Fiber Bragg Grating Sensor System to monitor the inelastic response of concrete sections in new tunnel linings subjected to earthquake loading, Computer-Aided Civil and Infrastructure Engineering 30, 636 - 653 (2015).

7. N.A. Hoult, W.A. Take, C. Lee \& M. Dutton, Experimental accuracy of two dimensional strain measurements using Digital Image Correlation, Engineering Structures 46, 718 - 726 (2013).

8. D. J. White, W.A Take \& D. Bolton, Soil deformation measurement using particle image velocimetry (PIV) and photogrammetry, Geotechnique 53(7), 619 - 631 (2003). 